\title{
Não mais faltarão hortaliças, e uma boa prosa, aos anjos do céu!
}

\author{
Paulo Eduardo de Melo
}

Embrapa Hortaliças, C. Postal 218, 70359-970, Brasília - DF, paulo@cnph.embrapa.br

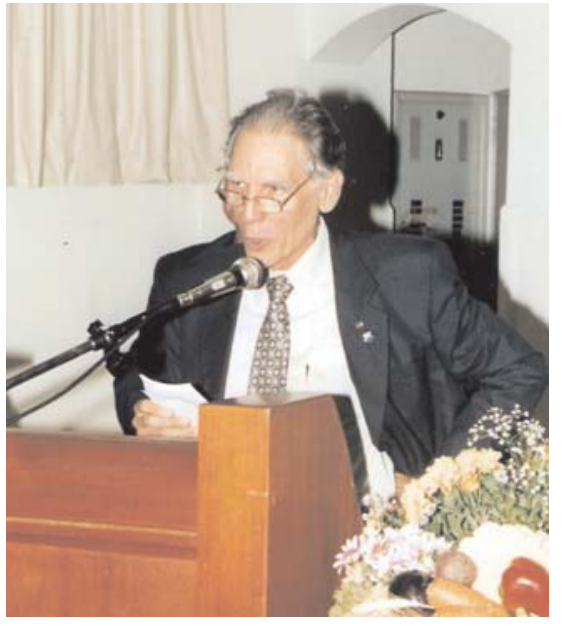

$\mathrm{P}$ oucas vezes foi tão difícil produzir um texto! Mas, como era típico do próprio Filgueira dizer: Para que servem as dificuldades, se não para tornar a vida mais emocionante, encerrando o dito com a sua risada característica? E assim é: até mesmo neste momento, de escrever sobre ele, é dele que parte a inspiração; é dele a mão que ajuda, como tantas e tantas vezes aconteceu certamente com a maioria de nós, assistidos pelo Manual de Olericultura e pelo Novo Manual de Olericultura.

Tive a felicidade de conhecê-lo por seus livros e também pessoalmente e, sobretudo, de trabalhar com ele, na época na seleção de genótipos em batata, em um programa conjunto da Empresa Goiana de Pesquisa Agropecuária (EMGOPA), hoje AGENCIARURAL, e a Embrapa Hortaliças. Desta colaboração restaram, muito mais que dois conjuntos de clones-elite, excelentes parentais, e um trabalho publicado (Peixoto et al., 2002), uma sólida amizade e profundos respeito e admiração. A convivência com o Filgueira, iniciada bem no começo da minha carreira profissional, cristalizou em mim a certeza de que as pessoas que realmente contam na Olericultura nacional provêm da mais nobre cepa!
Além do prazer de compartilhar o dia-a-dia com alguém de tamanha educação e de ótimo humor, dois fatos marcaram de forma indelével a minha memória durante a nossa convivência: (1) a sua disposição genuína, o seu entusiasmo juvenil pelo doutorado, em nada esmaecidos pelas inúmeras voltas que já havia dado em torno do sol, de forma alguma assoberbados pela vasta experiência profissional que já detinha, e (2), alguns anos mais tarde, o indeferimento do seu pedido ao CNPq de bolsa de produtividade, pela mais inusitada das razões: baixa produção científica. Nenhuma outra razão poderia estar mais distante da verdade! Irreverente, alegre, entusiasmado como era, não se abalou e seguiu o seu caminho, semeando hortaliças por corações afora, colhendo extensionistas, produtores, professores e pesquisadores.

Esse Grande Homem nasceu em Recife, Pernambuco, em 17 de novembro de 1937, e passou parte da infância e a adolescência no Rio de Janeiro. Seu espírito inquieto levou-o às Minas Gerais, onde se formaria em Agronomia, em 1961, pela Universidade Rural do Estado de Minas Gerais, hoje Universidade Federal de Viçosa. Desde então, não houve limites para a sua dedicação à Olericultura, atuando, muitas vezes simultaneamente, como extensionista, pesquisador e professor, com uma capacidade ímpar de, entre produtores, tornar-se um hortelão; entre alunos, ser mais um deles; entre doutores, ser um verdadeiro doutor. Das montanhas mineiras, nosso Personagem mudou-se para Cunha, São Paulo, onde atuou por um ano como extensionista da Secretaria de Estado de Agricultura, para em seguida, voltar à universidade, em Viçosa, para o curso de mestrado, concluído com êxito em 1965. Permaneceu em Viçosa até 1967, na função de extensionista responsável pela li- gação ensino-pesquisa-extensão em Olericultura.

Naquele mesmo ano, deixou o friozinho úmido de Viçosa para viver no calor seco dos descampados goianos, em Anápolis. Em 1967 entrou na ACARGoiás (depois EMATER-GO, hoje, AGENCIARURAL) como pioneiro: foi o primeiro extensionista a coordenar um programa de incentivo à produção de hortaliças em Goiás. Alguns anos mais tarde, nosso Empreendedor seria novamente pioneiro, juntamente com seu colega de mestrado, Peter Ernst Sonnenberg: foram deles os primeiros passos da pesquisa estadual com hortaliças, em uma caminhada que resultou na criação da EMGOPA, Empresa Goiana de Pesquisa Agropecuária (hoje também AGENCIARURAL), que o contratou em 1975 e onde permaneceu até 1993 . Os resultados das pesquisas de ambos e a intervenção direta do Filgueira levaram para Goiás a primeira indústria de processamento de tomate, a Paoletti, que contratava sua produção em Morrinhos, $130 \mathrm{~km}$ ao sul de Goiânia. Mais tarde, a então Arisco, onde o Manual de Olericultura era Manual de Sobrevivência, deixou de comercializar somente temperos à base das também hortaliças alho e pimenta e introduziu em sua linha o extrato e, posteriormente, muitos outros produtos de tomate. Aquela semente, lançada pelo Filgueira e pelo Prof. Peter, representa hoje $85 \%$ do tomate brasileiro para processamento industrial e sustenta um agronegócio que inclui doze indústrias de processamento. Poucos profissionais colheram tanto resultado!

Durante o período em que permaneceu em Anápolis, nosso Incansável foi também professor de Economia Rural na Faculdade de Ciências Econômicas de Anápolis, atualmente pertencente à Universidade Estadual de Goiás (UEG). Em 1981, tornou-se oficialmente Notá- 
vel: foi declarado sócio honorário da Associação Brasileira de Horticultura $(\mathrm{ABH})$, à época Sociedade de Olericultura do Brasil (SOB). Em 1988 voltou para São Paulo como Aprendiz, desta vez para a UNESP, em Jaboticabal, onde, em 1991, concluiu o doutorado com um excelente trabalho sobre interação genótipo x ambiente em batata (Filgueira et al., 1995). De São Paulo, nosso Doutor voltou brevemente para Anápolis, para, em seguida, partir para o Triângulo Mineiro, onde, de 1993 a 1997, foi Professor Titular de Olericultura na Universidade Federal de Uberlândia, por onde se aposentou.

Porém, a aposentadoria era sapato que não cabia em seu pé e nosso Irrequieto não parou. Em 2000, lançou o Novo Manual de Olericultura, abrangendo 60 hortaliças e dedicado, de forma muito especial a estudantes e extensionistas (vide "Prefácio a um novo livro”, em Filgueira, 2000). Em 2001, nosso Insigne tornar-se-ia consultor do curso de Agronomia da UEG Unidade Universitária de Ipameri, a convite do seu discípulo, o profissional com quem mais conviveu, Nei Peixoto, passando de 2003 a 2006, a exercer as funções de Professor de Olericultura e Coordenador do Curso de Agronomia. Esse Apaixonado apaixonou-se também pela UEG, ao ponto de, já doente, chorar, cada vez que imaginava não poder voltar ao convívio acadêmico ou re-abrir seu consultório sentimental, como as- sim ele denominava o seu escritório, local preferido pelos estudantes para curarem suas mágoas (Peixoto, comunicação pessoal). Usando bengala e com dificuldades de andar, compareceu à formatura da $5^{\text {a. }}$ turma de Agronomia da UEG, levado por Nei Peixoto, onde, segundo o Nei, "conversou, deu gargalhadas, brincou; como era de seu feitio”. Em 2006, foi indicado Presidente de Honra do XLVI Congresso Brasileiro de Olericultura, realizado em Goiânia, GO, em uma justíssima homenagem por toda a sua contribuição à Olericultura nacional. A partir de 2007, nosso Admirável Colega passou a definir-se como escritor, consultor e palestrante (Batatashow, 2007).

Foi-se de nós, em 20 de fevereiro deste ano, em Anápolis, o amigo, o agrônomo de todos os dias, o paraquedista nas horas vagas, pé-de-valsa de tantos bailes de formatura e jantares de confraternização nos CBOs, Fernando Antonio Reis Filgueira, professor, mestre, doutor, enfim um grande profissional. Diversas autoridades, incluindo membros dos poderes legislativo e executivo, nas esferas municipal, estadual e federal, além de representantes do Ministério da Agricultura, Pecuária e Abastecimento, compareceram às exéquias, em uma evidente demonstração da Estatura atingida por essa Extraordinária Pessoa. Para ele, todavia e com toda certeza, muito mais importante foi o comparecimento dos amigos e as inú- meras manifestações de admiração e carinho daqueles que não puderam comparecer e confortar seus familiares. Nosso religioso sem religião, partiu.

Prezado Filgueira, sentimos imensamente a sua falta. Em parte, preenchemos sua ausência com tudo o que contigo e com seus livros, segundo você mesmo, sua maior realização (Batatashow, 2007), conseguimos aprender. Aqueles que viverem com coerência e ética, trabalhando com afinco, terão a virtude de reencontrar-te.

\section{AGRADECIMENTOS}

Sou imensamente grato aos Drs. Nei Peixoto, da UEG - Unidade Universitária de Ipameri, e Gilmar Henz, da Embrapa Hortaliças, pela revisão do manuscrito e pelas informações acrescentadas.

\section{REFERÊNCIAS}

BATATA-SHOW. 2007. Personalidades: Fernando Antonio Reis Filgueira. Batata-show 7: 12-13.

FILGUEIRA FAR. 2000. Novo manual de olericultura. Viçosa: Editora UFV. 402p.

FILGUEIRA FAR; BANZATTO DA; MASCA MGCC; CASTELLANE PD. 1995. Interação genótipo $\mathrm{x}$ ambiente em batata. Horticultura Brasileira 13: 134-141.

PEIXOTO N; FILGUEIRA FAR; MELO PE de; BUSO JA; MONTEIRO JD; BRAZ LT; PURQUERIO LFV; HAMASSAKI RI. 2002. Seleção de clones de batata para microclimas de altitude no Planalto Central. Horticultura Brasileira 20: 348-441. 